\title{
ENETS Consensus Guidelines for the Standards of Care in Neuroendocrine Neoplasms: Systemic Therapy - Chemotherapy
}

DOI:

$10.1159 / 000473892$

\section{Document Version}

Accepted author manuscript

Link to publication record in Manchester Research Explorer

Citation for published version (APA):

Antibes Consensus Conference participants (2017). ENETS Consensus Guidelines for the Standards of Care in Neuroendocrine Neoplasms: Systemic Therapy - Chemotherapy. Neuroendocrinology.

https://doi.org/10.1159/000473892

\section{Published in:}

Neuroendocrinology

\section{Citing this paper}

Please note that where the full-text provided on Manchester Research Explorer is the Author Accepted Manuscript or Proof version this may differ from the final Published version. If citing, it is advised that you check and use the publisher's definitive version.

\section{General rights}

Copyright and moral rights for the publications made accessible in the Research Explorer are retained by the authors and/or other copyright owners and it is a condition of accessing publications that users recognise and abide by the legal requirements associated with these rights.

\section{Takedown policy}

If you believe that this document breaches copyright please refer to the University of Manchester's Takedown Procedures [http://man.ac.uk/04Y6Bo] or contact uml.scholarlycommunications@manchester.ac.uk providing relevant details, so we can investigate your claim.

\section{OPEN ACCESS}




\section{ENETS Consensus Guidelines for the Standards of Care in Neuroendocrine Neoplasms. Systemic Therapy 2: Chemotherapy}

Rocio Garcia-Carbonero ${ }^{1}$, Anja Rinke ${ }^{2}$, Juan W. Valle ${ }^{3}$, Nicola Fazio ${ }^{4}$, Martyn Caplin ${ }^{5}$, Vera Gorbounova $^{6}$, Juan O’Connor ${ }^{7}$, Barbro Eriksson ${ }^{8}$, Halfdan Sorbye ${ }^{9}$, Mathew Kulke ${ }^{10}$, Jie Chen ${ }^{11}$, Jenny Falkerby ${ }^{8}$, Frederico Costa ${ }^{12}$, Wouter de Herder $^{13}$, Catherine Lombard-Bohas ${ }^{14}$, Marianne Pavel $^{15}$; all other Antibes Consensus Conference participants*

1. Medical Oncology Department, Hospital Universitario Doce de Octubre, Madrid, Spain

2. Division of Gastroenterology and Endocrinology, University Hospital Marburg (UKGM), Marburg, Germany

3. Department of Medical Oncology, University of Manchester, Institute of Cancer Sciences / The Christie NHS Foundation Trust, Manchester, United Kingdom

4. Unit of Gastrointestinal Medical Oncology and Neuroendocrine Tumors, European Institute of Oncology, Milan, Italy

5. Neuroendocrine Tumour Unit, Royal Free Hospital, London, United Kingdom

6. Department of Oncology, Institution of Russian Academy of Medical Sciences, Moscow, Russia

7. Department of Clinical Oncology, Institute Alexander Fleming, Buenos Aires, Argentina

8. Department of Endocrine Oncology, Uppsala University Hospital, Uppsala, Sweden

9. Deptartment of Oncology, Haukeland University Hospital, Bergen, Norway

10. Dana-Farber Cancer Institute, Harvard Medical School, Boston, Massachusetts, USA

11. Department of Gastroenterology, The First Affiliated Hospital, Sun Yat-sen University, Guangzhou, China

12. Hospital Sirio Libanes, Sao Paulo, Brazil

13. Department of Internal Medicine, Division of Endocrinology, ENETS Centre of Excellence Rotterdam, Erasmus MC, Rotterdam, the Netherlands

14. Medical Oncology Department, Hôpital Edouard Herriot, Hospices Civils de Lyon, Lyon, France

15. Department of Hepatology and Gastroenterology, Campus Virchow Klinikum, Charité Universitätsmedizin Berlin, Berlin, Germany

* For an alphabetical list of all other Antibes Consensus Conference participants, see Appendix

\section{Corresponding author:}

Rocio Garcia-Carbonero

Medical Oncology Department

Hospital Universitario Doce de Octubre.

Avenida de Cordoba, s/n, 28041 Madrid, Spain

Phone: +34 913908926

Fax: +34914603310

Email: rgcarbonero@gmail.com

\section{Abstract}

Systemic chemotherapy is indicated in progressive or bulky advanced pancreatic neuroendocrine tumors (NETs) and in grade 3 (G3) neuroendocrine neoplasms (NENs) as per ENETS Guidelines. Chemotherapy may be considered in NETs of other sites (lung, thymus, stomach, colon, rectum) under certain conditions (e.g., when Ki-67 is at a high level (upper G2 range), in rapidly progressive disease and/or after failure of other therapies, or if somatostatin receptor imaging is negative). An ENETS 
Consensus Conference was held in Antibes (2015) to ellaborate guidelines on the standards of care of different diagnostic procedures and therapeutic interventions in NENs. This article provides guidance on chemotherapy including therapeutic indications, dosing schedules, adverse events (including prevention and management), drug interactions and evaluation of treatment effect for the chemotherapy agents most commonly used in NENs (streptozocin, dacarbazine, streptozocin, fluoropyrimidines, platinum compounds, etoposide and irinotecan).

\section{Introduction}

Systemic therapies that are established as standards of care (SOCs) for neuroendocrine neoplasms (NENs) include somatostatin analogues (SSA), alpha interferon (IFN), novel targeted agents (everolimus, sunitinib), and chemotherapy. Other novel targeted agents (e.g. bevacizumab, axitinib, pazopanib) have been recently investigated in phase II trials in neuroendocrine tumors (NETs), but are not currently approved for the management of NETs and thus will not be covered by these guidelines. SOCs for SSA, IFN and targeted therapy will be covered in a separate chapter. The current manuscript will cover SOCs related to chemotherapy. 


\section{Indication}

Systemic chemotherapy is indicated in progressive or bulky advanced pancreatic NETs and in grade 3 (G3) NENs as per ENETS Guidelines [1,2]. Chemotherapy may be considered in NETs of other sites (lung, thymus, stomach, colon, rectum) under certain conditions (e.g., when Ki-67 is at a high level (upper G2 range), in rapidly progressive disease and/or after failure of other therapies, or if somatostatin receptor imaging is negative) [1,2].

Streptozocin (STZ)-based chemotherapy is one of the treatment options in G1/G2 pancreatic NET, and is preferably recommended in patients with higher tumor burden, with or without associated clinical symptoms, and/or in patients with significant tumor progression within a 6 to 12 months time frame [3-6]. The combination of STZ with doxorubicin proved to be more effective than STZ with 5fluorouracil (5FU) in the pivotal randomized study by Moertel [5]. However, the use of doxorubicin is limited by its cumulative cardiotoxicity. Chemotherapeutic options after failure of STZ-based chemotherapy include the following: temozolomide (TMZ) +/- capecitabine [7-12], dacarbazine [1315], oxaliplatin combinations with fluoropyrimidines (5-FU or capecitabine) $[16,17]$ and irinotecanbased therapy [18]. Although data for TMZ-based chemotherapy are still limited, it may replace STZbased therapy in pancreatic NEN, if STZ is not available, and may be considered in NET G3 and in high risk NET of other primary sites (e.g., pulmonary NET) [19-21].

In high grade neuroendocrine carcinomas (NEC G3), chemotherapy is an essential part of the multimodality approach for localized disease and the mainstay of care in advanced or metastastatic disease [1]. Platinum-based chemotherapy is generally indicated provided the patient has adequate organ function and performance status [22-24]. The combination of cisplatin and etoposide, or alternative regimens substituting carboplatin for cisplatin, or irinotecan for etoposide, are recommended as first-line therapy [25-28]. Since response rates of these regimens are lower in patients with Ki-67 in the lower range of G3 (21-55\%), other treatment options may be explored in these patients (particularly for G3 NEN of GI origin), although no studies to date have demonstrated improved efficacy of these alternative regimens in this setting. While 2nd-line regimens have not been evaluated rigorously, options include temozolomide-, irinotecan- or oxaliplatin-based schedules as main alternatives [1]. Efficacy of chemotherapy in NET G3 is presently uncertain.

\section{Dosing Schedules: Drug disposition, posology and mode of administration}

The most widely used chemotherapy regimens or those supported by more solid evidence in gastroenteropancreatic NENs are depicted in Tables 1, 2 \& 3. The pharmaceutical presentation, drug disposition, route and mode of administration of the most commonly employed cytotoxic agents are briefly summarized below. 


\section{Doxorubicin (DOX)}

Doxorubicin is administered IV by rapid infusion (2-3 minutes). It does not cross the bloodbrain barrier, but does cross the placenta and is distributed into breast milk. Doxorubicin undergoes rapid metabolism in the liver. Dose should be adjusted in case of liver impairment (50\% reduction for bilirubin levels of $1.2-3 \mathrm{mg} / \mathrm{dl}$; a $75 \%$ dose reduction is advised in obese patients and if bilirubin levels are $>3 \mathrm{mg} / \mathrm{dl}$, although it is not generally recommended to treat NEN patients with this degree of liver dysfunction). Doses do not need to be adjusted for renal function impairment unless severely compromised (25\% dose reduction is advised if glomerular filtration rate (GFR) $<10 \mathrm{ml} / \mathrm{min}$, although it may be more appropriate not to treat patients with this degree of renal dysfunction) [29,30].

\section{Streptozocin (STZ)}

Streptozocin is administered IV by rapid injection or short (15-30 minutes) infusion. A single dose of $1500 \mathrm{mg} / \mathrm{m}^{2}$ should not be exceeded due to high risk of nephrotoxicity. Metabolism and drug disposition of streptozocin has been barely studied in humans, but in animal studies up to $20 \%$ of the drug is excreted by the kidney [29,31]. STZ should thus be used with caution in patients with preexisting renal disease as it may increase the risk of drug exposure and drug-related toxicity including renal damage.

\section{$\underline{\text { Dacarbazine }}$}

Dacarbazine may be administered by IV bolus injection or as a short-term infusion (15 -30 minutes). Dacarbazine is inactive until metabolised by cytochrome P450 (CYP450) to form the reactive Ndemethylated species HMMTIC and MTIC. Dacarbazine is metabolized mainly in the liver and 20-50 $\%$ of the drug is excreted unmodified by the kidney. Dose reductions are not required in patients with mild to moderate renal or hepatic insufficiency. Elimination of dacarbazine is prolonged, however, in patients with combined renal and hepatic dysfunction, and it should therefore be used with caution in this context [29,32].

\section{Temozolomide (TMZ)}

TMZ is administered orally as hard capsules of $5 \mathrm{mg}, 20 \mathrm{mg}, 100 \mathrm{mg}, 140 \mathrm{mg}, 180 \mathrm{mg}$ or $250 \mathrm{mg}$. The capsules shall be administered in a fasting state and must not be opened or chewed. If vomiting occurs following drug ingestion, a second dose should not be administered that day.

TMZ is spontaneously hydrolyzed to the active species, 3-methyl-(triazen-1-yl)imidazole-4carboxamide (MTIC). MTIC is further hydrolyzed to 5-amino-imidazole-4-carboxamide (AIC) and to methylhydrazine, which is believed to be the active alkylating species. TMZ cytotoxicity is thought to be primarily due to alkylation of DNA at the O6 and N7 positions of guanine [33].

TMZ is rapidly absorbed and crosses the blood-brain barrier. The major route of TMZ elimination is renal. TMZ plasma clearance is independent of age, renal or liver function. However, caution should be exercised when TMZ is administered in patients with severe liver or renal function impairment, as available data are very limited in these populations [29,34]. 
5-FU is administered IV by rapid injection or short infusion, and may also be given as a continuous IV infusion over 24-48 hours (or even longer) through a portable pump. Following a single IV injection approximately $15 \%$ of the dose is excreted unchanged in the urine within 6 hours. The remainder is mostly metabolised in the liver. 5-FU readily enters the cerebrospinal fluid and brain tissue. Dose adjustments are recommended in patients with poor nutritional status, impaired hepatic or renal function, or limited bone marrow reserve (e.g. extensive prior irradiation) [35,36].

\section{Capecitabine (CAP)}

Capecitabine is an oral fluoropyrimidine rationally designed to generate 5-FU preferentially in tumour tissue. After oral administration it is rapidly absorbed, and extensively metabolised in the liver and tumor tissues to 5-FU via a three-step enzymatic cascade [37]. Dihydropyrimidine dehydrogenase (DPD) activity is the rate-limiting step in 5-FU catabolism. Deficiency of DPD may lead to increased toxicity of capecitabine and 5-FU. No dose has proven to be safe for patients with complete absence of DPD activity. For patients with partial DPD deficiency (such as those with heterozygous mutations in the DPYD gene), and where the benefits of capecitabine are considered to outweigh the risks, capecitabine may be given with extreme caution and frequent monitoring with dose adjusment according to toxicity. There is insufficient data to recommend a specific dose in patients with partial DPD activity as measured by a specific test $[38,39]$.

Capecitabine is administered orally as film-coated tablets of $150 \mathrm{mg}$ and $500 \mathrm{mg}$. Tablets should be swallowed with water within 30 minutes after a meal. It is predominantly excreted in urine $(96 \%$ of administered dose), with minimal faecal excretion $(<3 \%)$. Capecitabine is contraindicated in patients with severe renal dysfunction (creatinine clearance $(\mathrm{CrCl})<30 \mathrm{ml} / \mathrm{min}$ ). In patients with moderate renal impairment, a dose reduction to $75 \%$ for a starting dose of $1250 \mathrm{mg} / \mathrm{m}^{2}$ is recommended (no dose reduction required for a starting dose of $\left.1000 \mathrm{mg} / \mathrm{m}^{2}\right)$. In patients with mild renal impairment ( $\mathrm{CrCl}$ of $51-80 \mathrm{ml} / \mathrm{min}$ ) no dose adjustment is needed. Insufficient data are available in patients with hepatic impairment to provide dose adjustment recommendations. No dose adjustment is recommended for elderly patients although they should be monitored more carefully as their risk of severe toxicity is greater $[29,37]$.

\section{Cisplatin (Cis-Diamine-Dichloro-Platinum, CDDP)}

Cisplatin is usually administered by IV infusion over 1 to 2 hours (a longer infusion time of 6 to 8 hours may decrease gastrointestinal and renal toxicities). Intensive pre- and postreatment IV hydration (3-4 litres of saline solution over a minimum of 6 hours for doses above $50 \mathrm{mg} / \mathrm{m}^{2}$, together with magnesium and potassium supplementation) is required to force diuresis and prevent renal toxicity. If vigorous hydration is insufficient to maintain an adequate urinary output $(\geq 100 \mathrm{ml} / \mathrm{hour}$ recommended), an osmotic diuretic may be administered (e.g. mannitol). Cisplatin may interact with metal aluminium to form a black precipitate of platinum. All aluminium-containing IV sets, needles, catheters and syringes should therefore be avoided $[29,40]$.

There is good uptake of cisplatin by the kidneys, liver and intestine. Penetration into the cerebrospinal fluid is poor although significant amounts of cisplatin can be detected in intracerebral tumours. The elimination of intact drug and metabolites occurs primarily through the urine (20-80\% during the first 24 hours). Use is therefore contraindicated in patients with pre-existing renal impairment and also in patients with a history of allergic reaction to other platinum compounds. Dose adjustments are not required in patients with liver dysfunction $[29,40]$ 


\section{Carboplatin (CycloButane DiCarboxylic Acid, CBDCA)}

Carboplatin is usually administered as a 1 hour IV infusion. Aluminium-containing equipment should not be used. Carboplatin is excreted primarily in urine, with recovery of $65 \%$ of administered dose within 24 hours. Patients with $\mathrm{CrCl}<60 \mathrm{ml} / \mathrm{min}$ are therefore at increased risk of severe myelosuppression. Nevertheless, the Calvert formula permits to determine carboplatin dosage adjusted to renal function: Dose $(\mathrm{mg})=$ target AUC $(\mathrm{mg} / \mathrm{ml} \times \mathrm{min}) \times$ [GFR $\mathrm{ml} / \mathrm{min}+25]$. Insufficient data exist, however, on the use of carboplatin in patients with $\mathrm{CrCl} \leq 15 \mathrm{ml} / \mathrm{min}$ to permit a recommendation for treatment $[29,40,41]$.

\section{Oxaliplatin (OX)}

Oxaliplatin is administered as a 2 to 6-hour IV infusion, and must always precede the administration of 5-fluorouracil. It does not require hyperhydration. Platinum is predominantly excreted in urine [42,43]. No dose adjustments are required in patients with mild renal impairment. Those with moderate renal impairment, treatment may be initiated at standard doses but toxicities and renal function should be closely monitored. Oxaliplatin has not been studied in patients with severe renal dysfunction. No specific dose adjustment is required for patients with abnormal liver function tests nor for elderly patients $[29,43]$.

\section{Etoposide (VP-16)}

Etoposide is generally given by IV injection (30-60 minutes) although it is also available as soft capsules of $50 \mathrm{mg}$ and $100 \mathrm{mg}$ for oral intake. Hypotension after rapid IV administration has been reported, so longer infusion times may be required depending on patient's tolerance. If etoposide injection comes into contact with skin or mucosa, immediately wash thoroughly with soap and water. The capsules should be taken on an empty stomach $[43,44]$.

Etoposide has relatively poor penetration into the cerebrospinal fluid. Following IV administration, $42-67 \%$ of the dose is recovered in urine and $0-16 \%$ in faeces. Impaired hepatic or renal function may increase etoposide concentration in tissues. Dose should be reduced to $75 \%$ in patients with $\mathrm{CrCl}$ of $15-50 \mathrm{~mL} / \mathrm{min}$. Data are not available in patients with $\mathrm{CrCl}<15 \mathrm{~mL} / \mathrm{min}$ and further dose reductions or alternative treatment options should be considered in these patients. No specific dosing guidelines exist for patients with impaired liver function [46].

\section{Irinotecan (CPT-11)}

Irinotecan is administered by IV infusion over 30 to 90 minutes. Irinotecan is metabolized by a carboxylesterase (present in intestinal mucosa, plasma and liver) into a highly active metabolite, SN38, which is further converted to inactive glucuronide (SN-38G) by UGT1A (uridine diphosphate glucuronosyltransferase). 55\% of administered dose is excreted as unchanged drug (33\% in faeces and $22 \%$ in urine) $[47,48]$.

In patients with bilirubinemia of 1.5 to 3 times above the upper limit of normal (ULN), irinotecan clearance decreases by about $40 \%$ and dose should be adjusted accordingly. Irinotecan should not be given to patients with plasma bilirubin $>3$ xULN. Its use is also contraindicated in patients with chronic inflammatory bowel disease and/or bowel obstruction. No specific dosing recommendations are provided for patients with renal impairment nor for elderly patients $[49,50]$. 


\section{Adverse events (AEs)}

The most common side effects of the individual cytotoxic agents are summarized below. For more comprehensive information regarding potential AEs the reader is referred to the summary of product characteristics (SPCs) of each individual drug ellaborated by marketing authorization holders (MAH) following regulatory agencies' requirements. It should also be noted that additive effects may occur when several of these drugs are combined in a given treatment regimen. Reported rates of adverse events of most commonly used chemotherapy regimens in NENs are summarized in Table 4 (data are derived from clinical trials in NENs when available, or from detailed reports of retrospective NEN series or clinical trials conducted in GI cancer in the absence of disease-specific clinical trials).

\section{$\underline{\text { Doxorubicin }}$}

Common side effects include myelosuppression (anemia, leucopenia, thrombocytopenia), nausea and vomiting (moderately emetogenic), mucositis, anorexia, diarrhea, cardiotoxicity (tachyarrythmia, bradycardia, bundle branch block, decrease of left ventricular ejection fraction (LVEF), congestive heart failure), and alopecia. Doxorubicin is a potent, radiosensitizing agent, and recall phenomena may occur. Caution is advised to prevent extravasation as it can lead to severe cellulitis and vesication [49].

In order to avoid cardiomyopathy, the cumulative total lifetime dose of doxorubicin should not exceed $450-550 \mathrm{mg} / \mathrm{m}^{2}$ body surface area. In patients with cardiac risk factors such as prior thoracic irradiation, prior or concurrent treatment with potentially cardiotoxic agents, chronic hypertension, prior coronary, valvular or myocardial heart damage, age over 70 years or children, the total cumulative dose should not exceed $400 \mathrm{mg} / \mathrm{m}^{2}$ and cardiac function should be closely monitored in these patients [29,50].

\section{$\underline{\text { Streptozocin }}$}

Renal toxicity of streptozocin includes proteinuria, hypophosphatemia, azotemia and renal tubular acidosis. Mild proteinuria is one of the first signs of renal toxicity and may herald further deterioration of renal function. Although generally mild, renal toxicity is dose-related and cumulative, and severe cases have been reported. Adequate hydration may help reduce the risk of nephrotoxicity. Other major toxicities are nausea and vomiting, which may be severe if appropriate antiemetic prophylaxis is not implemented. In addition, mild to moderate abnormalities of glucose tolerance, liver dysfunction (elevated liver enzymes, hypoalbuminemia), diarrhea, and hematological toxicity have been observed in some patients. Extravasation may cause severe tissue lesions and necrosis. Streptozocin is mutagenic and carcinogenic [29,31].

\section{Dacarbacine}

The most common side effects of dacarbazine (occuring in $>10 \%$ of treated patients) include nausea and vomiting (highly emetogenic), injection site pain and delayed myelosuppression (cumulative, dose dependent). Other less common AEs (occuring in 1-10\% of patients) are alopecia, anorexia, taste disturbances (metallic taste), flu-like syndrome, photosensitivity and rash. Liver and renal toxicities are rare $[29,32]$.

\section{Temozolomide}

Very common adverse reactions include mild nausea, vomiting, constipation, anorexia, rash, headache 
and fatigue. Convulsions were commonly reported in patients receiving TMZ as monotherapy or concurrent with RT for glioblastoma or glioma, although they have not been reported in other nonCNS tumors. Haematologic toxicity is common although generally mild (grade $\geq 3$ anemia, leucopenia and thrombocytopenia: $3 \%, 3 \%$ and $14 \%$ when used as monotherapy). However, the incidence of grade 3-4 lymphopenia has been observed in over $40 \%$ of patients after 4 months of therapy and may remain in $>30 \%$ for 12 months following treatment discontinuation. The overall incidence of opportunistic infections is $10 \%$ (up to $20 \%$ in patients receiving more than 7 months of treatment). Prophylaxis for Pneumocystis jiroveci pneumonia and varicella-zoster, as well as cytomegalovirus shall be considered in patients with prolonged TMZ treatment. Liver enzymes elevations are common and cases of hepatic failure have been reported. Liver toxicity may occur several weeks after TMZ administration. Liver function tests should therefore be performed prior to each treatment cycle and several weeks after treatment discontinuation. TMZ should not be used in patients with hypersensitivity to dacarbazine $[29,34]$.

\section{5-Fluorouracil}

Common side effects of 5-FU include myelosuppression (leucopenia, thrombocytopenia, pancytopenia), diarrhea, nausea and vomiting, anorexia, asthenia, mucositis, and palmar-plantar erythrodysesthesia syndrome (dysaesthesia of the palms and soles that progress to pain and tenderness, with associated symmetrical swelling and erythema of the hand and foot; more common with protracted infusion or oral fluoropyrimidines). Alopecia is not uncommon, particularly in females, but is reversible. Electrocardiographic changes (exceptionally including QT prolongation), angina pectoris-like chest pain and rarely myocardial infarction have been also associated with 5-FU therapy, and are attributed to drug-induced vasospasm. Special attention is advisable in patients with a history of heart disease or severe atheromatosis, and in those who experience chest pain during treatment courses. Central nervous system toxicity (dizziness, pyramidal signs, ataxia and somnolence) is uncommon. Severe or even lethal toxicity may occur in patients with DPD deficiency (3-5\% of the population) $[29,51]$.

\section{Capecitabine}

Capecitabine's toxicity profile is very similar to that of 5 -FU, but it is associated with less hematological toxicity and a greater incidence of hand-foot syndrome and liver toxicity (most commonly hyperbilirubinemia). Most adverse reactions are reversible and do not require permanent discontinuation of therapy, although doses may need to be withheld or reduced. Caution is advised in patients with a history of heart disease or DPD deficiency [29,52].

\section{Cisplatin}

The most frequently reported AEs of cisplatin (occuring in $>10 \%$ of patients) are hematological (leukopenia, thrombocytopenia and anemia), gastrointestinal (anorexia, nausea, vomiting and diarrhea), ear disorders (hearing impairment), renal disorders (renal failure, hyperuricaemia) and fever. Peripheral sensory neurotoxicity is also common, and varies from paresthesia in fingers to ataxic gait, which might be transient or irreversible. Neurological, renal, bone marrow and ear toxicity are generally dose-related and cumulative. Ototoxicity may be more severe in children. Intense hydration is essential to prevent nephrotoxicity. Allergic reactions may occur. Cross reactions have been reported with all platinum compounds [29,53,54]. 


\section{Carboplatin}

The toxicity profile of carboplatin is similar to that of cisplatin, but it is moderately emetogenic (in contrast to cisplatin that is highly emetogenic) and it is associated with less nephrotoxicity, ototoxicity and neurotoxicity. Myelosuppression is the dose-limiting toxicity of carboplatin. At very high dosages severe liver toxicity has been reported [29,53].

\section{Oxaliplatin}

Oxaliplatin is almost universally administered in combination with fluoropyrimidines, increasing the incidence and severity of gastrointestinal (diarrhea, nausea, vomiting and mucositis), hematological (neutropenia, thrombocytopenia) and neurological toxicity induced by fluoropyrimidines when administered alone.

The dose limiting toxicity of oxaliplatin is neurological. It involves a sensory peripheral neuropathy characterised by dysaesthesia and/or parasthesia of the extremities often triggered by cold. These symptoms occur in up to $95 \%$ of treated patients, are dose-related and cumulative, and generally improve or revert upon treatment discontinuation. An acute syndrome of pharyngolaryngeal dysesthesia occurs in $1-2 \%$ of patients, and is characterised by subjective sensations of dysphagia or dyspnoea, without any objective evidence of respiratory distress (no cyanosis or hypoxia, no stridor or wheezing). These symptoms are rapidly reversible upon infusion discontinuation even in the absence of treatment (no need for antithistamines, corticoids or bronchodilators), and should be distinguished from hypersensitivity reactions. Other less common side effects include muscle spasms (often jaw spasms), balance disorders, throat or chest pressure/discomfort/pain, and cranial nerve dysfunctions (ptosis, diplopia, dysphonia, abnormal tongue sensation or dysarthria, visual disorders) [53,55].

\section{$\underline{\text { Etoposide }}$}

The dose-limiting effect of etoposide is myelosuppression. Nausea and vomiting are also common (they occur in $31-43 \%$ of patients). Other gastrointestinal toxicities include anorexia (10-13\%), stomatitis (1-6\%) and diarrhea (1-13\%). Reversible alopecia has been observed in about 2/3 of patients. Transient hypotension may occur following rapid IV administration. Anaphylactic type reactions have been reported to occur during or immediately after IV administration of etoposide. Caution is advised in patients with low serum albumin levels and those with impaired renal or liver function due to increased risk of toxicity. Etoposide is mutagenic and carcinogenic [29].

\section{$\underline{\text { Irinotecan }}$}

The most frequent dose-limiting toxicities of irinotecan include hematological toxicity (neutropenia, anemia and thrombocytopenia) and delayed diarrhea (occurring more than 24 hours after drug administration). The concurrent occurrence of neutropenia and diarrhea confers a particular risk of severe infections. Irinotecan also commonly induces a transient acute cholinergic syndrome, which is characterized by early diarrhea, abdominal cramps, vasodilatation, sweating, dizziness, visual disturbances, miosis, lacrimation and increased salivation occurring during or within the first 24 hours after drug infusion. This syndrome is generally easily controlled with subcutaneous atropine administration $(0.25 \mathrm{mg})$. Other side effects include alopecia, and transient and mild to moderate increases in serum levels of alanine transferase (ALT), aspartate transaminase (AST), alkaline 
phosphatase or bilirubin. Liver toxicity is more commonly observed when irinotecan is administered in combination with other drugs such as fluoropyrimidines [48].

The main active metabolite, SN-38, is detoxified by UGT1A1 to SN-38 glucuronide. Individuals with a congenital UGT1A1 deficiency (Crigler-Najjar or Gilbert's syndrome) are at increased risk of irinotecan toxicity. A reduced initial dose should be considered for these patients [47].

Of note, as irinotecan solution contains sorbitol (excipient), it is not suitable for patients with fructose intolerance.

\section{Prevention, management and dose adjustments for AEs}

\section{Prevention of adverse events}

Antiemetic prophylaxis should be prescribed following ASCO, NCCN or MASCC-ESMO guidelines. For highly emetogenic agents (e.g. cisplatin, dacarbazine, streptozocin), a 3-drug combination of a neurokinin 1 antagonist (aprepitant, fosaprepitant, netupitant), a 5-hydroxytryptamine-3 antagonist (granisetron, ondansetron, palonosetron, dolasetron, tropisetron, ramosetron) and dexamethasone should be offered. For agents with a moderate emetic risk (e.g. oxaliplatin, carboplatin, doxorubicin, irinotecan, temozolomide), prophylaxis with 5-hydroxytryptamine-3 antagonists and dexamethasone is recommended. Prophylaxis with corticosteroids alone is advised for low emetogenic drugs (e.g. 5-FU) $[56,57]$.

Primary febrile neutropenia (FN) prophylaxis with granulocyte colony-stimulating factors (G-CSF) is not generally indicated for chemotherapy regimens usually employed in the treatment of NENs (risk of FN $<20 \%$ ). Secondary prophylaxis should follow ASCO guidelines [58].

Doxorubicin-induced cardiac toxicity may be prevented by limiting the cumulative total lifetime dose to $450-550 \mathrm{mg} / \mathrm{m}^{2}$ (400 $\mathrm{mg} / \mathrm{m}^{2}$ in patients with cardiac risk factors). Cardiac function (LVEF) should be assessed before patients undergo treatment with doxorubicin and must be monitored throughout therapy, particularly with higher cumulative doses. Treatment should be discontinued in case significant cardiac function deterioration is documented [49,50].

Cisplatin-induced renal toxicity may be prevented by intense hydration prior and after drug administration by decreasing renal and urinary concentration of the drug and its metabolites [54]. Adequate hydration is also important to reduce the risk of streptozocin-induced renal toxicity. Carboplatin dose should be adjusted to glomerular filtration rate.

Oxaliplatin-induced acute laryngopharyngeal dysaesthesia and sensory peripheral neuropathy may be minimized by avoiding cold exposure and by increasing drug infusion time. If functional impairment persists until the next cycle, treatment with oxaliplatin should be delayed or discontinued [55].

Fluoropyrimidines should not be given to patients with known complete absence of DPD activity. Patients with partial DPD deficiency must be treated with extreme caution and frequent monitoring with dose adjusments according to toxicity [39].

Chemotherapy should be given with caution to high risk patients who have recently undergone surgery, have a history of high-dose irradiation of bone marrow-bearing areas (pelvis, spine, ribs, etc.), have received prior myelosuppressive chemotherapeutic agents or peptide-receptor radionuclide therapy (PRRT), have a widespread involvement of bone marrow by metastatic tumours, have reduced renal or liver function, or a poor nutritional state.

Treatment cycles with myelosuppresive drugs should not begin if the neutrophil count is less than 1,500 cells $/ \mathrm{mm}^{3}$ or the platelet count is less than 100,000 cells $/ \mathrm{mm}^{3}$, unless caused by malignant 
disease.

More frequent INR monitoring or a switch to subcutaneous heparine is recommended for patients on oral anticoagulants due to potential interactions between oral anticoagulants and many antineoplastic agents.

Viral hepatitis due to hepatitis B or C virus (HBV/HCV) reactivation may occur during chemotherapy. Baseline serologies are recommended in all patients and experts in liver disease should be consulted if positive for adequate monitorization and management. Antiviral therapy should be started for HBsAgpositive/anti-HBc-positive patients before or concurrently with cancer therapy. Antivirals may be initiated in HBsAg-negative/anti-HBc-positive patients if they are to receive cancer therapies associated with a high risk of reactivation; alternatively, they may be monitored with HBV DNA and ALT levels and initiate on-demand antivirals if reactivation occurs. [59].

Live attenuated vaccines should be avoided but inactivated vaccines may be used.

Patients should be informed that there may be a potential risk in driving or using complex machinery after chemotherapy administration due to confusion or lethargy.

\section{Management and dose adjustments for most common AEs}

Nausea and vomiting. The development of new antiemetic agents and prophylaxis regimens has dramatically reduced chemotherapy-induced emesis. If nausea and vomiting develop despite adequate adherence to prophylaxis guidelines, symptomatic and supportive measures (oral or parenteral) shall be administered to prevent dehydration, and intensification of antiemetic prophylaxis shall be implemented in subsequent cycles. No chemotherapy dose adjustments are generally required.

Mucositis. Adequate oral hygiene and dental care is advised prior to initiation of therapy. Treatment of mucositis relies on symptom management and prevention of complications, which includes pain control, fluid and nutritional support, and prophylaxis/treatment of secondary infections. In mild cases, pain can be controlled with locally applied products containing mucosal coating agents and lidocaine or doxepin. In severe or persistent cases, treatment with local or systemic corticosteroids and oral or parenteral analgesics may be considered. Secondary candidiasis is a common complication that is generally treated with topical antifungal therapy. In patients that develop grade $\geq 2$ mucositis, chemotherapy should be interrupted and next cycle of therapy delayed until mucositis recovers to grade $\leq 1$. Dose should be reduced in subsequent cycles by $20-30 \%$ in patients that develop grade 3-4 mucositis.

Diarrhea. Early intervention is advised to prevent complications such as dehydration and electrolyte disturbances. General measures include an astringent diet, oral rehydration with fluids that contain water, salt, and sugar, and intensive loperamide therapy. Somatostatin analogues and opium derivatives may be employed in severe or refractory cases. In patients that develop chemotherapyinduced grade $\geq 2$ diarrhea (to be distinguished from hormone-related diarrhea in functioning NETs), chemotherapy should be interrupted and next cycle of therapy delayed until diarrhea recovers to grade $\leq 1$. Dose should be reduced in subsequent cycles by $20-30 \%$ in patients that develop grade $3-4$ diarrhea.

Hand-foot syndrome. Supportive measures include frequent hydrating, emollient and keratolytic creams (e.g. 10\% urea cream), high-potency topical corticosteroids, wound care for erosions and ulcerations to prevent infection, and pain control. Treatment interruption is advised in patients that develop grade $\geq 2$ hand-foot syndrome, with symptoms typically improving within 1 to 2 weeks. Treatment may be reinitiated once it recovers to grade $\leq 1$, generally at reduced doses. 
Hematological toxicity. Supportive measures including blood and platelet trasfusions may be indicated in severe cases. Chemotherapy should be interrupted in case of grade $\geq 2$ toxicity, and next cycle delayed until recovery to grade $\leq 1$. Dose in subsequent cycles should be reduced in case of grade 3-4 toxicity.

Neutropenic fever. Early intervention with empiric broad spectrum antibiotics is recommended even in the absence of clinical or microbiological documentation of infection. Specific antibiotic, antifungal or antiviral agents and adequate supportive measures shall be instituted as needed. G-CSF therapy may be considered in high risk patients or severe episodes. Chemotherapy should be interrupted and next cycle delayed until complete resolution of the episode and neutrophil count recovery to grade $\leq 1$. Dose should be reduced by 20-30\% and/or G-CSF support shall be considered in subsequent cycles.

Renal or liver toxicity. Management includes avoidance of hepato- or nephrotoxic drugs, supportive measures and symptomatic therapy. Chemotherapy should be interrupted in case of grade $\geq 2$ toxicity, and next cycle delayed until recovery to grade $\leq 1$ or to baseline analytical levels. Dose reductions should be considered in subsequent cycles.

Neurotoxicity. Although several neuroprotective agents have been tested (e.g., calcium/magnesium, vitamin E, glutathione, amifostine, xaliproden, or venlafaxine), no solid evidence supports their use for the prevention or treatment of platium-induced neuropathy in routine clinical practice. Chemotherapy should be interrupted in case of persistent grade $\geq 2$ toxicity, and next cycle delayed until recovery to grade $\leq 1$. Dose in subsequent cycles should be reduced by $20-30 \%$ in case of grade 3-4 toxicity. Appropriate analgesics for neuropathic pain may be required.

Drug extravasation. The degree of damage is dependent on the type of drug, drug concentration, extravasation site and duration of tissue exposure to drug damage. Extravasated drugs are classified according to their potential for causing damage as 'vesicant' (e.g. doxorubicin), 'irritant' (e.g. streptozocin, dacarbazine, etoposide, fluorouracil, platinum compounds, irinotecan) and 'nonvesicant' (e.g. monoclonal antibodies) [60]. Extravasated anthracyclines, antibiotics and alkylating agents should be localized (apply dry cold compresses for 20 minutes 4 times daily for 1-2 days) and neutralized with specific antidotes (e.g. topical dimethyl sulfoxide (DMSO) and dexrazosane for anthracyclines). Extravasated taxanes, vinca alkaloids and platinum salts should be dispersed (apply dry warm compresses for 20 minutes 4 times daily for 1-2 days) and diluted (administer agents increasing resorption such as hyaluronidase for vinca alkaloids and taxanes). Local injection of dexamethasone or hydrocortisone may be administered to minimise tissue necrosis. Oral analgesics or anti-inflammatory agents may also be used. Surgical debridment may be necessary in severe cases.

\section{Monitoring of adverse events}

Patients should be regularly followed during chemotherapy every 2 to 6 weeks (depending on treatment schedule). Toxicity should be graded according to the universal Common Terminology Criteria for Adverse Events (CTCAE) (latest update v5.0, currently under review) [61].

Before starting chemotherapy the following investigations are recommended:

- Thorough physical exam and assessment of clinical condition and comorbidities. Baseline performance status (PS), body weight, hight and blood pressure should be recorded.

- Review of concomitant medication and assessment of potential drug interactions.

- Laboratory: blood cell count, glucose, electrolytes, renal and liver function tests.

- Hepatitis B and C virus screening.

- ECG and LVEF for potentially cardiotoxic drugs. 
During chemotherapy the following monitoring investigations are recommended:

- Assessment of clinical condition, PS and body weight at least every 4-6 weeks.

- Blood cell count, glucose, electrolytes, renal and liver function tests prior to each treatment cycle (more often if clinically required).

- Routine viral monitoring and treatment when indicated in patients with a history of, or at high risk of, HCV or HBV.

- Monitoring of cardiac function (ECG and echocardiography or MUGA scan) every 2-3 months for potentially cardiotoxic drugs (more often if clinically indicated).

\section{Evaluation of treatment effect}

\section{Biochemical response}

Before starting chemotherapy the following biomarkers should be measured:

- Chromogranin A (CgA) or Neuron-specific Enolase (NSE) if CgA within normal limits and/or in poorly differentiated neuroendocrine carcinomas.

- 5-hydroxy-indolacetic acid (5-HIAA) urine excretion in 24 hours (collect urine on acetic acid or hydrochloric acid following local laboratory procedures) or in blood (serum or plasma) in patients with possible or definitive carcinoid syndrome.

- Additional tumor markers depending on tumor type only if clinically indicated (i.e gastrin, VIP, glucagon, insulin,...).

During chemotherapy assessment of the following biomarkers are recommended:

- Elevated tumor markers on baseline assessment should be monitored throughout therapy every 3 months or in parallel with imaging assessments, or at any time if clinically indicated. 


\section{Tumor response}

Before starting chemotherapy the following imaging procedures should be performed:

- Conventional abdominal imaging - either multiphasic contrast-enhanced CT, including arterial and portal venous acquisition phases, or MRI - should be performed within 4 weeks prior to initiation of chemotherapy.

- Thoracic imaging with a CT scan should be considered to be done at least once in every NEN, and should be definitively performed in patients in whom thoracic lesions have been identified by other imaging procedures (e.g. chest X-ray or somatostatin-receptor scintigraphy), in patients with rectal primaries and in patients with poorly differentiated or grade 3 NENs.

During chemotherapy the following imaging procedures are recommended:

- Abdominal imaging with the same technique as that performed at baseline, and thoracic CT scan if abnormal baseline findings, should be performed every 3 months while on chemotherapy or earlier if clinically indicated. Greater time intervals may be considered in individual patients with longlasting disease stabilization. The use of RECIST 1.1 criteria to assess response and progressionfree survival is recommended although not mandatory in patients not enrolled in clinical trials.

\section{Drug interactions}

Drug interactions should be carefuly checked in cancer patients before initiating chemotherapy due to the narrow therapeutic index of most antineoplastic agents, and the potential for these interactions to lead to ineffective treatment or to severe or lethal side-effects. Here we summarize the most common known drug interactions of cytotoxic agents usually employed in the management of NENs. For more comprehensive information the reader is referred to the drugs SPCs.

\section{$\underline{\text { Doxorubicin }}$}

Doxorubicin undergoes metabolism via CYP450 and is a substrate for the Pgp transporter. Concomitant administration of CYP450 inhibitors (e.g. ketoconazole, cymetidine, ritonavir, erythromycin, grapefruit juice, etc.) increase doxorubicin plasma concentrations and may thereby increase toxicity, whereas coadministration of CYP450 inducers (e.g. rifampicin, corticoids, phenytoin, carbamazepine, barbiturates or herbal preparations containing St John's Wort/Hypericum perforatum) reduce doxorubicin exposure and may decrease efficacy. Doxorubicin may reduce oral bioavailability/absorption of digoxin and antiepileptic drugs (e.g. carbamazepine, phenytoin, valproate). Co-administration of heparin and doxorubicin can increase the rate of doxorubicin clearance. In addition, precipitates may form and lead to a loss of efficacy of both drugs [29,62].

\section{$\underline{\text { Streptozocin }}$}

Streptozocin's metabolism and drug interactions have been barely studied in humans. Streptozocin has been reported to prolong the elimination half-life of doxorubicin [29].

\section{Dacarbazine}

Dacarbazine-solution is chemically incompatible with heparin, hydrocortisone, L-cysteine and sodium hydrogen carbonate. Dacarbazine is metabolised in the liver by CYP450 (CYP1A1, CYP1A2, and CYP2E1) to its active metabolites HMMTIC and MTIC. This has to be taken into account if other drugs are co-administered which are metabolised by the same hepatic enzymes (inducers of these enzymes could increase toxicity, and inhibitors could decrease efficacy) [29,62]. 


\section{$\underline{\text { Temozolomide }}$}

TMZ does not undergo hepatic metabolism and exhibits low protein binding; it is therefore unlikely that it can affect the pharmacokinetics of other medicinal products. TMZ clearance is not altered by co-administration of dexamethasone, prochlorperazine, phenytoin, carbamazepine, ondansetron, H2 receptor antagonists, or phenobarbital. Co-administration with valproic acid was associated with a small decrease in TMZ clearance [29].

\section{Capecitabine and 5-Fluorouracil}

Various purines, pyrimidines, and antimetabolites (e.g. methotrexate, interferon, allopurinol, hydroxyurea, etc) have shown biochemical modulation of fluorouracil in in vitro test systems [29,38]. A synergistic cytotoxic interaction with folinic acid modestly increases 5-FU efficacy, particularly in colon cancer, but it also leads to increased toxicity. Pretreatment with cimetidine prior to IV fluorouracil decreases 5-FU clearance and increases 5-FU plasma concentrations. Increased phenytoin plasma concentrations have been reported during concomitant use with fluoropyrimidines [62]. Concomitant use of allopurinol may decrease fluoropyrimidine efficacy. Marked elevations of prothrombin time and INR have been reported in some patients taking capecitabine or 5-FU concomitantly with warfarin. Caution should be taken when using capecitabine or fluorouracil in conjunction with medications that inhibit DPD activity including some common antiviral agents (sorivudine or brivudine). A 4-week waiting period is advised between end of treatment with these antivirals and start of fluoropyrimidine therapy [63].

\section{$\underline{\text { Platinum compounds }}$}

Antioxidants such as sodium bisulphite might inactivate cisplatin before administration if present in IV fluids. Reduction of blood's lithium values has been reported in some cases following treatment with cisplatin, bleomycin and etoposide. Cisplatin and carboplatin may reduce the serum levels of phenytoin when used concurrently, likely due to reduced phenytoin absorption and/or increased metabolism. Phenytoin may also increase hepatic metabolism of platinum compounds, potentially decreasing their efficacy $[29,62]$.

\section{Etoposide}

Etoposide Injection contains ethanol, benzyl alcohol and polysorbate, which may be toxic in infants and young children. Phenylbutazone and salicylates may displace etoposide from plasma protein binding and increase drug exposure. Cyclosporin and cisplatin may reduce etoposide clearance and thereby increase its toxicity. Concomitant phenytoin or phenobarbital therapy is associated with increased etoposide clearance and reduced efficacy. Concomitant warfarin therapy may result in increased INR values, so close monitoring is recommended in these patients [29,62].

\section{Irinotecan}

Concomitant administration of neuromuscular blocking agents should be done with caution. Irinotecan decreases phenytoin absorption. Concomitant administration of strong CYP450 3A4 (CYP3A4) inhibitors or inducers may increase toxicity or reduce efficacy. The use of these drugs should therefore be avoided if posible while on irinotecan therapy, or irinotecan doses shall be reduced or increased accordingly $[29,62]$.

\section{Pregnancy and lactation}

Cytotoxic agents may be genotoxic and mutagenic, and can adversely affect human fertility or cause teratogenesis. Therefore, they should not be administered to pregnant women or those who are breast feeding. Men and women should use effective contraception during and up to 6 months after 
treatment. Cryopreservation of sperm and/or ovarian tissue may be offered to fertile patients with potentially curative disease.

\section{All other Antibes Consensus Conference participants}

Arnold, R. (Munich, Germany); Bartsch, D.K. (Department of Surgery, Philipps University, Marburg, Germany); Baudin, E. (Département de Médecine, Gustave Roussy, 114, rue Édouard-Vaillant, Paris South University, Villejuif Cedex 94805, France); Borbath, I. (Service de Gastroenterologie, Cliniques Universitaires St-Luc, Bruxelles, Belgium); Capdevila, J. (Vall d'Hebron University Hospital, Teknon Institute of Oncology, Barcelona, Spain); Couvelard, A. (Service de Pathologie, Hôpital Bichat, Paris, France); Cwikla, J.B. (Department of Radiology, Faculty of Medical Sciences, University of Warmia and Mazury, Olsztyn, Poland); Davies, P. (Neuroendocrine Tumour Unit, Royal Free Hospital, London, United Kingdom); Delle Fave, G. (Department of Digestive and Liver Disease, Ospedale Sant'Andrea, Rome, Italy); Ferone, D. (Department of Endocrine and Metabolic Sciences, University of Genoa, Genoa, Italy); Grozinsky-Glasberg S. (Neuroendocrine Tumor Unit, Endocrinology and Metabolism Service, Department of Medicine, Hadassah-Hebrew University Medical Center, Jerusalem, Israel); Gorbunova, V. (Department of Oncology, Institution of Russian Academy of Medical Sciences); Gross, D. (Department of Endocrinology \& Metabolism, Hadassah University Hospital, Mevasseret Tsion, Israel); Grossman, A. (Oxford Centre for Diabetes, Endocrinology and Metabolism, Churchill Hospital, Oxford, United Kingdom); Hicks R.J. (Cancer Imaging, the Peter MacCallum Cancer Centre, Melbourne); Hörsch, D. (Gastroenterology and Endocrinology Center for Neuroendocrine Tumors Bad Berka, Bad Berka, Germany); Tiensuu Janson, E. (Deptartment of Endocrine Oncology, Uppsala University Hospital, Uppsala, Sweden); Jensen, R.T. (Digestive Diseases Branch, NIH, Bethesda, Md., USA); Kaltsas, G. (Department of Pathophysiology, Division of Endocrinology, National University of Athens, Athens, Greece); Knigge, U. (Neuroendocrine Tumor Center of Excellence, Rigshospital, Copenhagen University Hospital, Copenhagen, Denmark); Kos-Kudla, B. (Department of Endocrinology, Medical University of Silesia, Katowice, Poland); Krenning, E.P., (Cyclotron Rotterdam BV, Erasmus MC, Rotterdam, The Netherlands); Kwekkeboom, D.J. (Department of Internal Medicine, Division of Nuclear Medicine, ENETS Centre of Excellence Rotterdam, Erasmus MC, Rotterdam, The Netherlands); Niederle, B. (Department of Surgery, Medical University of Vienna, Vienna, Austria); Nieveen van Dijkum, E.J.M. (Department of Surgery, Academic Medical Center, Amsterdam, the Netherlands); Öberg, K. (Department of Medical Sciences, Endocrine Oncology Unit, University Hospital, Uppsala, Sweden); O’Toole (D. NET Centre, St. Vincent's University and Department of Clinical Medicine, St James Hospital and Trinity College, Dublin , Ireland); Pape, U.-F. (Department of Hepatology and Gastroenterology, Campus Virchow Klinikum, Charité Universitätsmedizin Berlin, Berlin, Germany); Pascher, A. (Department of Surgery, CharitéUniversitaetsmedizin Berlin, Berlin, Germany); Perren A. (Institute of Pathology, University of Bern, Switzerland); Ramage, J. (Gastroenterology Department, Hampshire Hospitals NHS Trust, Hampshire, United Kingdom); Reed, N. (Beatson Oncology Centre, Gartnavel General Hospital, Glasgow, United Kingdom); Rindi, G. (Institute of Anatomic Pathology, Policlinico A. Gemelli, Università Cattolica del Sacro Cuore, Rome, Italy); Ruszniewski, P. (Department of Gastroenterology, Beaujon Hospital, Clichy, France); Scoazec, J.-Y. (Services de pathologie morphologique et moléculaire, Département de biologie et pathologie médicales, Gustave Roussy Cancer Campus, Villejuif, France); Sundin, A. (Department of Radiology, Inst. Surgical Sciences, Uppsala University, Uppsala University Hospital, Uppsala, Sweden); Toumpanakis, C. (Neuroendocrine Tumour Unit, Royal Free Hospital, London, United Kingdom); Vullierme M.-P. (Service de Gastroentérologie, Hôpital Beaujon, Clichy, France); Welin, S. (Department of Medical Sciences, Endocrine Oncology, Uppsala University, Sweden); Wiedenmann, B. (Department of Hepatology and Gastroenterology, Campus Virchow Klinikum, Charité Universitätsmedizin Berlin, Berlin, Germany) 


\section{REFERENCES}

1. Garcia-Carbonero R, Sorbye H, Baudin E, Raymond E, Wiedenmann B, Niederle B, et al; all other Vienna Consensus Conference participants: Consensus Guidelines for High Grade Gastro-EnteroPancreatic (GEP) Neuroendocrine Tumours and Neuroendocrine Carcinomas (NEC). Neuroendocrinology 2016;103:186-194.

2. Pavel M, O'Toole D, Costa F, Capdevila J, Gross D, Kianmanesh R, et al; all other Vienna Consensus Conference: Consensus Guidelines Update for the Management of Distant Metastatic Disease of Intestinal, Pancreatic, Bronchial Neuroendocrine Neoplasms (NEN) and NEN of Unknown Primary Site. Neuroendocrinology 2016;103:172-185.

3. Moertel CG, Hanley JA, Johnson LA: Streptozocin alone compared with streptozocin plus fluorouracil in the treatment of advanced islet-cell carcinoma. N Engl J Med 1980;303:1189-1194.

4. Eriksson B, Öberg K: An update of the medical treatment of malignant endocrine pancreatic tumors. Acta Oncol 1993; 32:203-208.

5. Moertel CG, Lefkopoulo M, Lipsity S, Hahn RG, Klaassen D: Streptozocin-doxorubicin, streptozocin-fluorouracil or chlorozotocin in the treatment of advanced islet-cell carcinoma. $\mathrm{N}$ Engl J Med 1992; 326: 519-523.

6. Eriksson B, Skogseid B, Lundqvist G, Wide L, Wilander E, Oberg K: Medical treatment and longterm survival in a prospective study of 84 patients with endocrine pancreatic tumors. Cancer 1990; 65:1883-1890.

7. Olsen IH, Sørensen JB, Federspiel B, Kjaer A, Hansen CP, Knigge U, et al: Temozolomide as second or third line treatment of patients with neuroendocrine carcinomas. The Scientific World Journal 2012;2012:170496.

8. Ekeblad S, Sundin A, Janson ET, Welin S, Granberg D, Kindmark H, et al: Temozolomide as monotherapy is effective in treatment of advanced malignant neuroendocrine tumors. Clin Cancer Res 2007;13:2986-2991.

9. Welin S, Sorbye H, Sebjornsen S, Knappskog S, Busch C, Oberg K: Clinical effect of temozolomide based chemotherapy in poorly differentiated endocrine carcinoma after progression on first line chemotherapy. Cancer 2011; 117:4617-4622.

10. Strosberg JR, Fine RL, Choi J, Nasir A, Coppola D, Chen DT, et al: First-line chemotherapy with capecitabine and temozolomide in patients with metastatic pancreatic endocrine carcinomas. Cancer 2011;117:268-275.

11. Saif MW, Kaley K, Brennan M, Garcon MC, Rodriguez G, Rodriguez T: A retrospective study of capecitabine/temozolomide (CAPTEM) regimen in the treatment of metastatic pancreatic neuroendocrine tumors (pNETs) after failing previous therapy. JOP 2013;14:498-501.

12. Fine RL, Gulati AP, Krantz BA, Moss RA, Schreibman S, Tsushima DA, et al: Capecitabine and temozolomide (CAPTEM) for metastatic, well-differentiated neuroendocrine cancers: The Pancreas Center at Columbia University experience. Cancer Chemother Pharmacol 2013;71:663670.

13. Altimari A, Badrinath K, Reisel H, Prinz RA: DTIC therapy in patients with malignant intraabdominal neuroendocrine tumors. Surgery 1987; 102:1009-1017.

14. Ramanathan RK, Cnaan A, Hahn RG, Carbone PP, Haller DG: Phase II trial of dacarbazine (DTIC) in advanced pancreatic islet cell carcinoma. Study of the Eastern Cooperative Oncology Group-E6282. Ann Oncol 2001; 12:1139-1143.

15. Mueller D, Krug S, Majumder M, Rinke A, Gress TM. Low dose DTIC is effective and safe in pretreated patients with well differentiated neuroendocrine tumors. BMC Cancer. 2016 Aug 18;16:645. 
16. Bajetta E, Catena L, Procopio G, De Dosso S, Bichisao E, Ferrari L, et al: Are capecitabine and oxaliplatin (XELOX) suitable treatments for progressing low-grade and high-grade neuroendocrine tumours? Cancer chemotherapy and pharmacology 2007;59:637-642.

17. Hadoux J, Malka D, Planchard D, Scoazec JY, Caramella C, Guigay J, et al: Post-first-line FOLFOX chemotherapy for grade 3 neuroendocrine carcinoma. Endocr Relat Cancer 2015;22:289-298.

18. Hentic O, Hammel P, Couvelard A, Rebours V, Zappa M, Palazzo M, et al: FOLFIRI regimen: an effective second-line chemotherapy after failure of etoposide-platinum combination in patients with neuroendocrine carcinomas grade 3. Endocrine-related cancer 2012; 19:751-757.

19. Cros J, Hentic O, Rebours V, Zappa M, Gille N, Theo-Anton N, et al: MGMT expression predicts response to temozolomide in pancreatic neuroendocrine tumors. Endocr Relat Cancer 2016 Jun 28. pii: ERC-16-0117. [Epub ahead of print] PubMed PMID: 27353036.

20. Schmitt AM, Pavel M, Rudolph T, Dawson H, Blank A, Komminoth P, et al: Prognostic and predictive roles of MGMT protein expression and promoter methylation in sporadic pancreatic neuroendocrine neoplasms. Neuroendocrinology 2014;100:35-44.

21. Kulke MH, Hornick JL, Frauenhoffer C, Hooshmand S, Ryan DP, Enzinger PC, et al: O6methylguanine DNA methyltransferase deficiency and response to temozolomide-based therapy in patients with neuroendocrine tumors. Clin Cancer Res 2009;15:338-345.

22. Moertel CG, Kvols LK, O’Connell MJ, Rubin J: Treatment of neuroendocrine carcinomas with combined etoposide and cisplatin. Evidence of major therapeutic activity in the anaplastic variants of these neoplasms. Cancer 1991; 68: 227-232.

23. Mitry E, Baudin E, Ducreux M, Sabourin JC, Rufié P, Aparicio T, et al: Treatment of poorly differentiated neuroendocrine tumors with etoposide and cisplatin. Br J Cancer 1999; 81:13511355.

24. Iwasa S, Morizane C, Okusaka T, Ueno H, Ikeda M, Kondo S, et al: Cisplatin and etoposide as first-line chemotherapy for poorly differentiated neuroendocrine carcinoma of the hepatobiliary tract and pancreas. Japanese Journal of Clinical Oncology 2010;40:313-318.

25. Di Meglio G, Massacesi C, Radice D, Boselli S, Pelosi G, Squadroni M, et al. Carboplatin with etoposide in patients with extrapulmonary "aggressive” neuroendocrine carcinoma. J Clin Oncol 2010; 28 suppl; abstr. e13072.

26. Kulke MH, Wu B, Ryan DP, Enzinger PC, Zhu AX, Clark JW, et al: A phase II trial of irinotecan and cisplatin in patients with metastatic neuroendocrine tumors. Digestive diseases and sciences 2006;51:1033-1038.

27. Lu Z, Li J, Lu M, Zhang XT, Li J, Zhou J, et al: Feasibility and efficacy of combined cisplatin plus irinotecan chemotherapy for gastroenteropancreatic neuroendocrine carcinomas. Medical Oncology 2013;30:1-5.

28. Nakano K, Takahashi S, Yuasa T, Nishimura N, Mishima Y, Sakajiri S, et al: Feasibility and efficacy of combined cisplatin and irinotecan chemotherapy for poorly differentiated neuroendocrine carcinomas. Japanese Journal of Clinical Oncology 2012;42:697-703.

29. The chemotherapy source book. Michael C. Perry (Ed). 2016. Philadelphia, Lippincot Williams \& Wilkinson. $5^{\text {th }}$ Edition.

30. Speth PA, van Hoesel QG, Haanen C: Clinical pharmacokinetics of doxorubicin. Clin Pharmacokinet 1988;15:15-31.

31. Weiss RB: Streptozocin: a review of its pharmacology, efficacy, and toxicity. Cancer Treat Rep 1982;66:427-438.

32. Al-Badr AA, Alodhaib MM: Dacarbazine. Profiles Drug Subst Excip Relat Methodol 2016;41:323-77. 
33. Newlands ES, Stevens MF, Wedge SR, Wheelhouse RT, Brock C: Temozolomide: a review of its discovery, chemical properties, pre-clinical development and clinical trials. Cancer Treat Rev 1997;23:35-61.

34. Koumarianou A, Kaltsas G, Kulke MH, Oberg K, Strosberg JR, Spada F, et al: Temozolomide in Advanced Neuroendocrine Neoplasms: Pharmacological and Clinical Aspects. Neuroendocrinology 2015;101:274-288.

35. Schilsky RL: Biochemical and clinical pharmacology of 5-fluorouracil. Oncology (Williston Park) 1998;12(10 Suppl 7):13-8.

36. Diasio RB, Johnson MR: The role of pharmacogenetics and pharmacogenomics in cancer chemotherapy with 5-fluorouracil. Pharmacology 2000;61:199-203.

37. Reigner B, Blesch K, Weidekamm E: Clinical pharmacokinetics of capecitabine. Clin Pharmacokinet 2001;40:85-104.

38. Di Paolo A, Danesi R, Falcone A, Cionini L, Vannozzi F, Masi G, et al: Relationship between 5fluorouracil disposition, toxicity and dihydropyrimidine dehydrogenase activity in cancer patients. Ann Oncol 2001;12:1301-1306.

39. Mercier C, Ciccolini J: Profiling dihydropyrimidine dehydrogenase deficiency in patients with cancer undergoing 5-fluorouracil/capecitabine therapy. Clin Colorectal Cancer 2006;6:288-296.

40. Go RS, Adjei AA: Review of the comparative pharmacology and clinical activity of cisplatin and carboplatin. J Clin Oncol 1999;17:409-422.

41. Alberts DS: Clinical pharmacology of carboplatin. Semin Oncol 1990;17 (4 Suppl 7):6-8.

42. Raymond E, Faivre S, Chaney S, Woynarowski J, Cvitkovic E: Cellular and molecular pharmacology of oxaliplatin. Mol Cancer Ther 2002;1:227-235.

43. Graham MA, Lockwood GF, Greenslade D, Brienza S, Bayssas M, Gamelin E: Clinical pharmacokinetics of oxaliplatin: a critical review. Clin Cancer Res 2000;6:1205-1218.

44. Carney DN: The pharmacology of intravenous and oral etoposide. Cancer 1991;67(1 Suppl):299302.

45. Joel S: The clinical pharmacology of etoposide: an update. Cancer Treat Rev 1996;22:179-221.

46. Stewart CF: Use of etoposide in patients with organ dysfunction: pharmacokinetic and pharmacodynamic considerations. Cancer Chemother Pharmacol 1994;34 Suppl:S76-83.

47. Garcia-Carbonero R, Supko JG: Current perspectives on the clinical experience, pharmacology, and continued development of the camptothecins. Clin Cancer Res 2002;8:641-661.

48. Fujita K, Sparreboom A: Pharmacogenetics of irinotecan disposition and toxicity: a review. Curr Clin Pharmacol 2010;5:209-217.

49. Carvalho C, Santos RX, Cardoso S, Correia S, Oliveira PJ, Santos MS, et al: Doxorubicin: the good, the bad and the ugly effect. Curr Med Chem 2009;16:3267-3285.

50. Jain D: Cardiotoxicity of doxorubicin and other anthracycline derivatives. J Nucl Cardiol 2000;7:53-62.

51. Macdonald JS: Toxicity of 5-fluorouracil. Oncology (Williston Park) 1999;13(7 Suppl 3):33-34.

52. Mikhail SE, Sun JF, Marshall JL: Safety of capecitabine: a review. Expert Opin Drug Saf 2010;9:831-841.

53. Hartmann JT, Lipp HP: Toxicity of platinum compounds. Expert Opin Pharmacother 2003;4:889901.

54. Pinzani V, Bressolle F, Haug IJ, Galtier M, Blayac JP, Balmès P: Cisplatin-induced renal toxicity and toxicity-modulating strategies: a review. Cancer Chemother Pharmacol 1994;35:1-9.

55. Hoff PM, Saad ED, Costa F, Coutinho AK, Caponero R, Prolla G, et al: Literature review and practical aspects on the management of oxaliplatin-associated toxicity. Clin Colorectal Cancer 2012;11:93-100. 
56. Basch E, Prestrud AA, Hesketh PJ, Kris MG, Feyer PC, Somerfield MR, et al: Antiemetics: American Society of Clinical Oncology clinical practice guideline update. J Clin Oncol 2011; 29:4189-4198.

57. Hesketh PJ, Bohlke K, Lyman GH, Basch E, Chesney M, Clark-Snow RA, et al: Antiemetics: American Society of Clinical Oncology Focused Guideline Update. J Clin Oncol 2016;34:381386.

58. Smith TJ, Bohlke K, Lyman GH, Carson KR, Crawford J, Cross SJ, et al: Recommendations for the Use of WBC Growth Factors: American Society of Clinical Oncology Clinical Practice Guideline Update. J Clin Oncol 2015;33:3199-3212.

59. Hwang JP, Somerfield MR, Alston-Johnson DE, Cryer DR, Feld JJ, Kramer BS, et al: Hepatitis B Virus Screening for Patients With Cancer Before Therapy: American Society of Clinical Oncology Provisional Clinical Opinion Update. J Clin Oncol. 2015 Jul 1;33(19):2212-20.

60. Perez Fidalgo JA, García Fabregat L, Cervantes A, Margulies A, Vidall C, Roila F; ESMO Guidelines Working Group: Management of chemotherapy extravasation: ESMO-EONS Clinical Practice Guidelines. Ann Oncol 2012;23 Suppl 7:vii167-73.

61. Common Terminology Criteria for Adverse Events (CTCAE) (v4.03: June 14, 2010). U.S. Department of Health and Human Services. National Institutes of Health. National Cancer Institute. http://evs.nci.nih.gov/ftp1/CTCAE/CTCAE_4.03_2010-06-14_QuickReference_5x7.pdf

62. Drug Development and Drug Interactions: Table of Substrates, Inhibitors and Inducers. U.S. Food and Drug Administration (FDA). http://www.fda.gov/ Drugs/DevelopmentApprovalProcess/DevelopmentResources/DrugInteractionsLabeling/ucm0936 64.htm

63. Okuda H, Nishiyama T, Ogura K, Nagayama S, Ikeda K, Yamaguchi S, et al: Lethal drug interactions of sorivudine, a new antiviral drug, with oral 5-fluorouracil prodrugs. Drug Metab Dispos 1997;25:270-273. 
Table 1. Streptozocin-based chemotherapy dosing regimens

\begin{tabular}{|c|c|c|c|c|}
\hline \multirow{2}{*}{$\begin{array}{l}\text { Reference } \\
\text { Moertel et al [5] }\end{array}$} & \multicolumn{4}{|c|}{ Treatment regimen } \\
\hline & STZ & $500 \mathrm{mg} / \mathrm{m}^{2}$ & days $1-5$ & q 6 weeks \\
\hline & DOX & $50 \mathrm{mg} / \mathrm{m}^{2}$ & days $1 \& 22$ & \\
\hline \multirow[t]{2}{*}{ Eriksson et al [6] } & STZ & $\begin{array}{l}500 \mathrm{mg} / \mathrm{m}^{2} \\
1 \mathrm{~g} / \mathrm{m}^{2}\end{array}$ & $\begin{array}{l}\text { days } 1-5, \\
\text { then day } 1\end{array}$ & q 3 weeks \\
\hline & DOX & $40 \mathrm{mg} / \mathrm{m}^{2}$ & $\begin{array}{l}\text { day } 3 \text {, } \\
\text { then day } 1\end{array}$ & \\
\hline \multirow[t]{2}{*}{ Moertel et al [5] } & STZ & $500 \mathrm{mg} / \mathrm{m}^{2}$ & days $1-5$ & q 6 weeks \\
\hline & 5-FU & $400 \mathrm{mg} / \mathrm{m}^{2}$ & days $1-5$ & \\
\hline \multirow[t]{2}{*}{ Eriksson et al [4] } & STZ & $\begin{array}{l}500 \mathrm{mg} / \mathrm{m}^{2} \\
1 \mathrm{~g} / \mathrm{m}^{2}\end{array}$ & $\begin{array}{l}\text { days } 1-5, \\
\text { then day } 1\end{array}$ & q 3 weeks \\
\hline & $5-\mathrm{FU}$ & $400 \mathrm{mg} / \mathrm{m}^{2}$ & $\begin{array}{l}\text { days } 1-3, \\
\text { then day } 1\end{array}$ & \\
\hline
\end{tabular}

STZ = Streptozocin; DOX = doxorubicin; 5-FU = 5-fluorouracil

Table 2. Platinum-based chemotherapy dosing regimens

\begin{tabular}{|c|c|c|c|c|}
\hline \multirow{2}{*}{$\begin{array}{l}\text { Reference } \\
\text { Mitry et al [23] }\end{array}$} & \multicolumn{4}{|c|}{ Treatment regimen } \\
\hline & Cisplatin & $45 \mathrm{mg} / \mathrm{m}^{2}$ & days $2-3$ & q 4 weeks \\
\hline & Etoposide & $100 \mathrm{mg} / \mathrm{m}^{2}$ & days $1-3$ & \\
\hline \multirow{2}{*}{ Di Meglio et al [25] } & Carboplatin & AUC 4-6 & day 1 & q 3 weeks \\
\hline & Etoposide & $100 \mathrm{mg} / \mathrm{m}^{2}$ & day $1-3$ & \\
\hline \multirow[t]{3}{*}{ Bajetta et al [16] } & CAPOX & & & q 3 weeks \\
\hline & - Oxaliplatin & $130 \mathrm{mg} / \mathrm{m}^{2}$ & day 1 (iv) & \\
\hline & - Capecitabine & $1000 \mathrm{mg} / \mathrm{m}^{2} / 12 \mathrm{~h}$ & days $1-14$ (po) & \\
\hline \multirow[t]{5}{*}{ Hadoux et al [17] } & FOLFOX & & & q 2 weeks \\
\hline & - Oxaliplatin & $85 \mathrm{mg} / \mathrm{m}^{2}$ & day 1 & \\
\hline & - Leucovorin & $400 \mathrm{mg} / \mathrm{m}^{2}$ & day 1 & \\
\hline & - $\quad$ 5-FU iv bolus & $400 \mathrm{mg} / \mathrm{m}^{2}$ & day 1 & \\
\hline & - $\quad$ 5-FU ci $46 \mathrm{~h}$ & $2400 \mathrm{mg} / \mathrm{m}^{2}$ & day 1 & \\
\hline \multirow[t]{5}{*}{ Hentic et al [18] } & FOLFIRI & & & q 2 weeks \\
\hline & - Irinotecan & $180 \mathrm{mg} / \mathrm{m}^{2}$ & day 1 & \\
\hline & - Leucovorin & $400 \mathrm{mg} / \mathrm{m}^{2}$ & day 1 & \\
\hline & - $\quad$ 5-FU iv bolus & $400 \mathrm{mg} / \mathrm{m}^{2}$ & day 1 & \\
\hline & - $\quad$ 5-FU ci 46h & $2400 \mathrm{mg} / \mathrm{m}^{2}$ & day 1 & \\
\hline
\end{tabular}

AUC - area under the curve; ci - continuous intravenous infusion; 5-FU - 5-fluorouracil; FOLFIRI - irinotecan, folinic acid and infusional 5-FU; FOLFOX - oxaliplatin, folinic acid and infusional 5-FU; iv - intravenous administration; po - oral administration; CAPOX oxaliplatin and capecitabine. 
Table 3. Dacarbazine and Temozolomide-based chemotherapy dosing regimens

\begin{tabular}{lllll}
\hline Reference & \multicolumn{2}{l}{ Treatment regimen } & & \\
\hline $\begin{array}{l}\text { Olsen et al [7] } \\
\text { Ekeblad et al [8] }\end{array}$ & Temozolomide & $200 \mathrm{mg} / \mathrm{m}^{2}$ & days 1-5 & $\mathrm{q} 4$ weeks \\
Strosberg et al [10] & Temozolomide & $175-200 \mathrm{mg} / \mathrm{m}^{2}$ & days 10-14 & $\mathrm{q} 4$ weeks \\
& Capecitabine & $750 \mathrm{mg} / \mathrm{m}^{2} / 12 \mathrm{~h}$ & days 1-14 & \\
Ramanathan et al [14] & Dacarbazine & $850 \mathrm{mg} / \mathrm{m}^{2}$ & day 1 & q 4 weeks \\
Mueller et al [15] & Dacarbazine & $650 \mathrm{mg} / \mathrm{m}^{2}$ & day 1 & q 4 weeks \\
\hline
\end{tabular}

Table 4. Toxicity of most commonly used chemotherapy regimens in NENs

\begin{tabular}{|c|c|c|c|c|c|c|c|c|c|c|c|c|c|c|c|c|c|c|}
\hline \multirow[t]{3}{*}{ Toxicity } & \multicolumn{18}{|c|}{ Treatment regimen } \\
\hline & \multicolumn{2}{|c|}{ STZ-DOX } & \multicolumn{2}{|c|}{ STZ-5FU } & \multicolumn{2}{|c|}{ CIS-VP16 } & \multicolumn{2}{|c|}{ CAPOX } & \multicolumn{2}{|c|}{ FOLFOX } & \multicolumn{2}{|c|}{ FOLFIRI } & \multicolumn{2}{|l|}{ TEM } & \multicolumn{2}{|c|}{ TEM-CAP } & \multicolumn{2}{|c|}{$\begin{array}{l}\text { Dacarbazin } \\
\mathrm{e}\end{array}$} \\
\hline & $\begin{array}{l}\text { all } \\
\text { grad } \\
\text { es }\end{array}$ & $\begin{array}{l}\text { grade } \\
3-4\end{array}$ & $\begin{array}{l}\text { all } \\
\text { grad } \\
\text { es }\end{array}$ & $\begin{array}{l}\text { grade } \\
3-4\end{array}$ & $\begin{array}{l}\text { all } \\
\text { grad } \\
\text { es }\end{array}$ & $\begin{array}{l}\text { grade } \\
3-4\end{array}$ & $\begin{array}{l}\text { all } \\
\text { grad } \\
\text { es }\end{array}$ & $\begin{array}{l}\text { grade } \\
3-4\end{array}$ & $\begin{array}{l}\text { all } \\
\text { grad } \\
\text { es }\end{array}$ & $\begin{array}{l}\text { grade } \\
3-4\end{array}$ & $\begin{array}{l}\text { all } \\
\text { grad } \\
\text { es }\end{array}$ & $\begin{array}{l}\text { grade } \\
3-4\end{array}$ & $\begin{array}{l}\text { all } \\
\text { grad } \\
\text { es }\end{array}$ & $\begin{array}{l}\text { grade } \\
3-4\end{array}$ & $\begin{array}{l}\text { all } \\
\text { grad } \\
\text { es }\end{array}$ & $\begin{array}{l}\text { grade } \\
3-4\end{array}$ & $\begin{array}{l}\text { all } \\
\text { grad } \\
\text { es }\end{array}$ & $\begin{array}{l}\text { grade } \\
3-4\end{array}$ \\
\hline Nausea & & & & & & & 62 & 5 & 64 & 5 & 72 & 13 & & & & & 31 & 0 \\
\hline Vomiting & 80 & 20 & 81 & 41 & 76 & 40 & 43 & 5 & 43 & 4 & 50 & 10 & & & 43 & 0 & 44 & 7 \\
\hline Diarrhea & 5 & 0 & 33 & 2 & & & 65 & 20 & 65 & 12 & 63 & 14 & & & & & 11 & 0 \\
\hline Mucositis & 5 & 0 & 19 & 5 & & & 22 & 1 & 22 & 2 & 51 & 10 & & & 31 & 2 & 10 & 1 \\
\hline Skin toxicity & & & & & & & 30 & 6 & 30 & 1 & 25 & 2 & & & 35 & 0 & & \\
\hline Fatigue & & & & & & & 38 & 6 & 21 & 4 & 46 & 4 & & & & & 5 & 0 \\
\hline Neurotoxicity & & & & & 72 & 0 & 57 & 5 & 57 & 4 & 10 & 0 & & & & & & \\
\hline Hear loss & & & & & 14 & 0 & & & & & & & & & & & & \\
\hline Renal toxicity & & & 29 & 7 & 6 & 0 & & & & & & & & & 6 & 0 & & \\
\hline Leucopenia & 57 & & 56 & 25 & 72 & 42 & & & & & & & 15 & 3 & & & 8 & \\
\hline Neutropenia & & & & & 70 & 64 & 27 & 7 & 58 & 43 & 76 & 24 & 6 & 3 & 71 & 8 & & \\
\hline Thrombocytopenia & 0 & & 8 & 6 & 24 & 12 & 23 & 7 & 24 & 4 & 16 & 0 & 37 & 14 & 74 & 11 & 3 & \\
\hline Anemia & & & & & 33 & 12 & 54 & 3 & & & 42 & 3 & 32 & 3 & 63 & 3 & 5 & \\
\hline
\end{tabular}

STZ = Streptozocin; CAP = Capecitabine; CAPOX = oxaliplatin and capecitabine; CIS-VP16 = cisplatin and etoposide; DOX = doxorubicin; 5-FU = 5-fluorouracil; FOLFIRI irinotecan, folinic acid and infusional 5-FU; FOLFOX - oxaliplatin, folinic acid and infusional 5-FU; iv - intravenous administration; po - oral administration; TEM = Temozolomide; TEM-CAP = Temozolomide and Capecitabine.

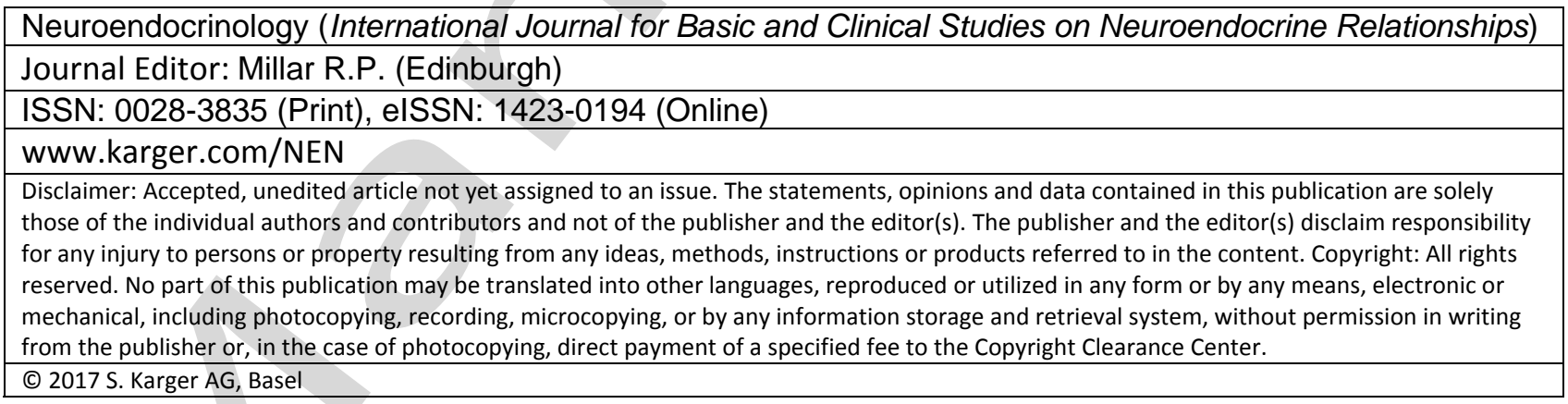

